\title{
N-Alkoxyamines: Synthesis, Properties, and Applications in Polymer Chemistry, Organic Synthesis, and Materials Science
}

\author{
Peter Nesvadba*
}

\begin{abstract}
This review describes methods for the synthesis of $\mathrm{N}$-alkoxyamines developed over the past 15 years. Applications of $\mathrm{N}$-alkoxyamines in living radical polymerization, macromolecular chemistry, stabilization of polymers or fluorescence sensing and imaging are discussed and emerging radical additions and cyclizations mediated by $\mathrm{N}$-alkoxyamines are presented.
\end{abstract}

Keywords: Alkoxyamines · Fluorescence sensing · Living radical polymerization - Nitroxides ·

Radical cyclizations

\section{Introduction}

N-Alkoxyamines 1.1, formally ethers of hydroxylamines $\mathbf{1 . 2}$, represent a broad family of compounds $\left(\mathrm{R}^{1}, \mathrm{R}^{2}=\mathrm{H}\right.$, alkyl, aryl; $\mathrm{R}^{3}=$ alkyl- or functionalized alkyl) (Scheme1). However, only a subset of all possible $\mathrm{N}$-alkoxyamines, namely those that are derived from disubstituted $\left(\mathrm{R}^{1}, \mathrm{R}^{2} \neq\right.$ $\mathrm{H})$ hydroxylamines $\mathbf{1 . 2}$ is known in the current literature by the term 'alkoxyamines'. The current renaissance of interest in their chemistry is due to the fact that they are key species involved in the rapidly developing field of controlled radical polymerization, the maturing but still innovation-receptive discipline of polymer stabilization and emerging applications in synthetic radical chemistry, fluorescence sensing, and imaging. A prerequisite for application of alkoxyamines in these fields is that the closely related nitroxide radicals $\mathbf{1 . 3}$ are stable (persistent) which further narrows the structural diversity. Therefore, only this kind of alkoxyamines, their preparation, properties, and applications are the topic of this micro review. Rather than trying to comprehen- sively cover the extensive literature, the most important achievements, trends and concepts are presented here. The vast field of nitroxide synthesis and properties is not discussed for reasons of space. The reader is instead referred to some excellent monographs [1][2] and reviews [3-9] on this subject.

\section{Synthesis of Alkoxyamines}

This overview summarizes new synthetic methods published in the last 15 years; a review [10] of older literature is available.

\subsection{Alkoxyamines via Trapping of C-Radicals with Nitroxides}

The most important synthesis of alkoxyamines by far is based on the radical coupling of $\mathrm{C}$-centered radicals with nitroxide radicals, a reaction proceeding at nearly diffusion controlled rate [11][12]. Numerous methods using this principle vary only in the way the $\mathrm{C}$-radical is generated. A straightforward approach is thermal or photochemical decomposition of a suit- able free radical initiator in the presence of a nitroxide. For example, heating azo-isobutyronitrile (AIBN) in benzene solution of 2,2,6,6-tetramethyl-piperidin-N-oxyl (TEMPO, 2.1) leads to the alkoxyamine $\mathbf{2 . 2}$ [13] and thermolysis of benzoyl peroxide in styrene solution containing excess of $\mathbf{2 . 1}$ affords the functionalized alkoxyamine $\mathbf{2 . 3}$ (Scheme 2) [14]. In this case the O-centered benzoyloxyl radicals do not react with $\mathbf{2 . 1}$ but add to styrene to form $\mathrm{C}$-centered radicals which readily couple with $\mathbf{2 . 1}$. Several other alkoxyamine syntheses take advantage of the fact that $\mathrm{O}$-centered radicals do not form stable coupling products with nitroxides but readily abstract $\mathrm{H}$ atoms from a variety of substrates such as alkanes, alkenes, alkylaromates, ethers, ketones or esters generating thus $\mathrm{C}$-centered radicals. Trapping of these C-radicals with nitroxides then affords alkoxyamines. Suitable sources of O-centered radicals are dialkyl peroxides, peresters or alkyl hydroperoxides. For example, generation of $t$-butoxyl radicals by gentle heating of thermally labile di- $t$-butyl peroxalate in ethyl benzene solution of $\mathbf{2 . 1}$ leads to the alkoxyamine $\mathbf{2 . 4}$<smiles>[R]ON([R])[R]</smiles><smiles>[R]N([R])O</smiles><smiles>[R]N([O])[O-]</smiles>

1.3 
[15] and photolysis of di- $t$-butyl peroxide in THF solution of $\mathbf{2 . 1}$ gives the alkoxyamine 2.5 [16] even at $-78{ }^{\circ} \mathrm{C}$. Pure regioisomers are formed in both cases because $t$-butoxyl radicals regioselectively abstract labile $\mathrm{H}$ atoms in benzylic or $\alpha$-to-oxygen positions. The copper-catalyzed decomposition of cheap $t$-butyl hydroperoxide in solutions of nitroxides in hydrocarbons such as ethyl benzene at $60-80{ }^{\circ} \mathrm{C}$ is of interest for large scale, industrial syntheses of alkoxyamines [17]. Nitroxides generally do not abstract $\mathrm{H}$-atoms from hydrocarbons. Exceptions are some perfluorinated [18] or photoexcited [19] nitroxides. However, slow Habstraction occurs at elevated temperatures with benzylic or allylic substrates. For instance, refluxing the solution of 4-hydroxyTEMPO 2.6 in $m$-xylene for $69 \mathrm{~h}$ afforded $51 \%$ yield of the alkoxyamine $\mathbf{2 . 7}$, the corresponding hydroxylamine was formed as a side product [20].

Several versatile syntheses of alkoxyamines use alkyl halides as C-radical precursors. Thus, their reaction with hydrazine and subsequent oxidation of the resulting alkyl hydrazines with $\mathrm{PbO}_{2}$ generates $\mathrm{C}$ centered radicals which are intercepted by nitroxides to give alkoxyamines, e.g. 3.1 (Scheme 3) [16]. One of the most general and mildest methods is the atom transfer radical addition (ATRA). It is the reaction of nitroxides with alkyl halides, copper (I) salts, e.g. $\mathrm{CuCl}$ or $\mathrm{CuBr}$ and generally a ligand helping to solubilize the $\mathrm{Cu}$ species [21-24]. Elemental copper may be added to reduce $\mathrm{Cu}$ (II) ions and hence speed up the reaction. 2,2'-Bipyridyls or readily available aliphatic tertiary polyamines, e.g. N,N,N',N",N"'-pentamethyldiethylenetriamine (PMDETA) are used as ligands. A large number of alkoxyamines from diverse nitroxides and variety of halides having the halogen atom $(\mathrm{Br}, \mathrm{Cl}, \mathrm{I})$ in activated position such as benzylic, allylic or $\alpha$ to a carbonyl group was prepared with this method. A typical example [24] is 3.3, derived from the so-called SG-1 nitroxide 3.2.

However, stoichiometric amounts of $\mathrm{Cu}$ salts and ligand are a problem for industrial-scale synthesis. Furthermore, nonactivated alkyl halides react poorly or not at all. Fortunately, these can be used in a synthesis [25] which generates C-radicals via halogen abstraction with tris(trimethyl)silyl radicals, produced from $\left.\left[\left(\mathrm{CH}_{3}\right)_{3} \mathrm{Si}\right)\right]_{3} \mathrm{SiH}$ and $t$-butyl hyponitrite. Iodides work best, giving fair yields of alkoxyamines, e.g. 3.4. Preparation of alkoxyamines from alkyl halides and nitroxides using tributyl tin hydride to generate the intermediate C-radicals was also demonstrated [26].

Renaud and coworkers reported that Balkyl catecholboranes, readily available via hydroboration of alkenes with catecholborane, react smoothly with TEMPO to give alkyl radicals. In the presence of an excess

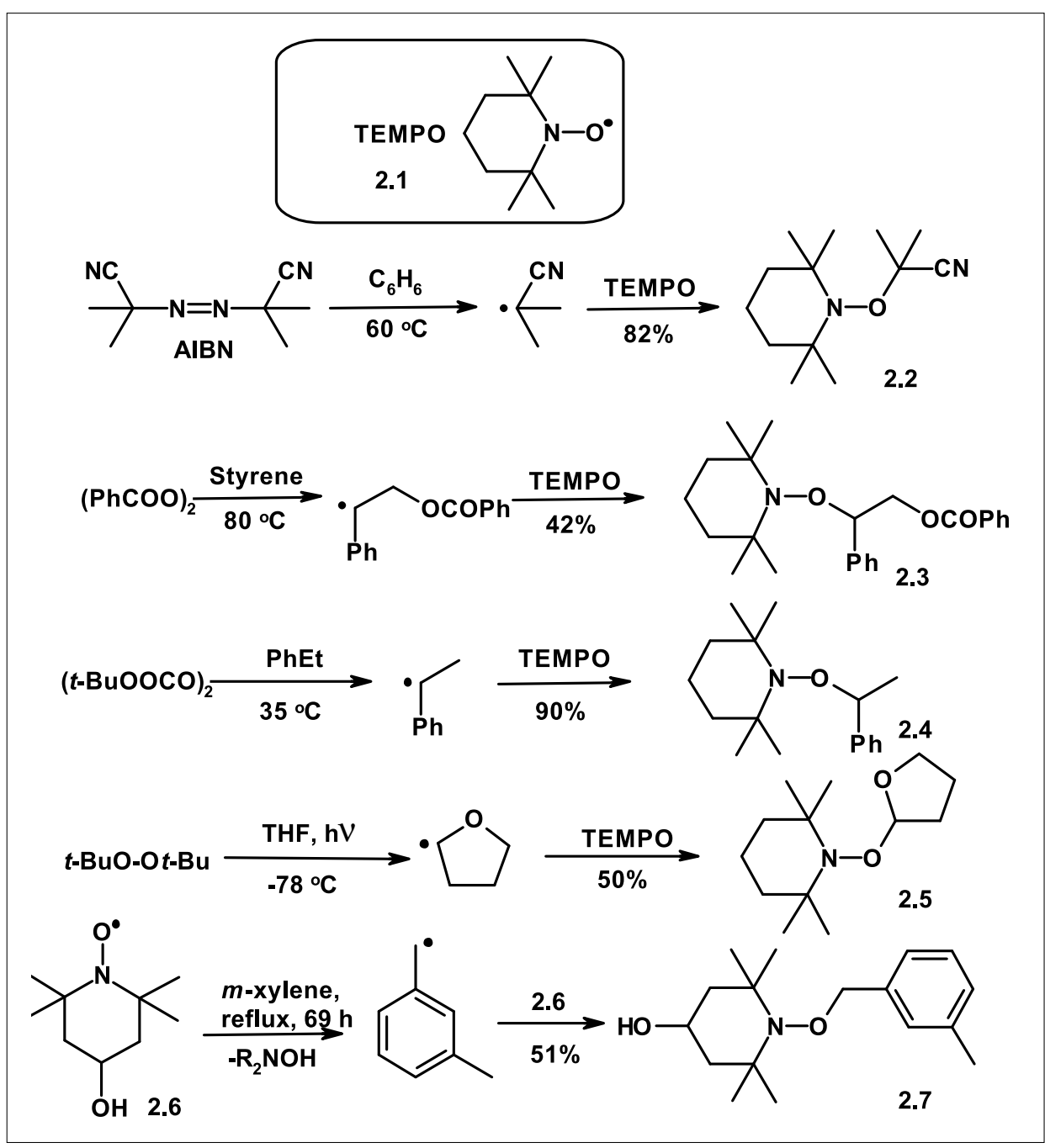

Scheme 2.

of TEMPO, the generated radicals are efficiently converted to alkoxyamine derivatives, for instance 3.5 [27].

The ATRA reaction was used to prepare polymeric alkoxyamines which have the $\mathrm{N}-\mathrm{O}$ bond incorporated into the polymer backbone [28]. For example, reaction of the bromo nitroxide 4.1 (Scheme 4) with $\mathrm{CuBr}$ in EtOAc afforded quantitative yield of polymer 4.2

Similar to the ATRA synthesis of alkoxyamines is the method recently reported by Thiessen and Wolff in which the intermediate C-radicals are generated via reaction of benzylic halides with $\mathrm{Zn}$ under vitamin B12 catalysis or with magnesium catalyzed by $\mathrm{SmI}_{2}$ [29]

Oxidation of ester enolates into C-centered radicals in the presence of nitroxides is the underlying principle of several syntheses of alkoxyamines [16][30][31]. Thus, a moderate yield of $\mathbf{5 . 1}$ was obtained via $\mathrm{Cu}$ (II) oxidation of Li-enolate of methyl isobutyrate (Scheme 5) [16]. TEMPO itself acts as an oxidizing agent for organometallic species [14][32] derived from $\mathrm{Li}, \mathrm{Mg}, \mathrm{Zn}, \mathrm{Cu}, \mathrm{Sm}, \mathrm{Ti}$ or $\mathrm{Zr}$ or lithiated 1,3-dithianes [33]. For example, addition of $n$-hexyllithium into excess of TEMPO solution in THF at $-78^{\circ} \mathrm{C}$ afforded the alkoxymine 5.2 in $78 \%$ yield [32]. Styrene and derivatives were successfully transformed into alkoxyamines using $\mathrm{Mn}$ (III) species and $\mathrm{NaBH}_{4}$. The mechanism involves addition of oxo-manganese species to styrene, trapping of the $\mathrm{C}$-radical intermediate with nitroxide followed by reductive cleavage of the oxo-manganese species with borohydride. The originally [34] used expensive Jacobsen catalyst was replaced by cheaper Mn salene complex [35][36] or $\mathrm{Mn}(\mathrm{OAc})_{3}$ [37]. Thiessen and Wolff [29] further improved the method by use of ultrasound and replacement of the stoichiometric amount of $\mathrm{Mn}(\mathrm{OAc})_{3}$ with a catalytic quantity and a cheap auxiliary oxidant $\left(\mathrm{KMnO}_{4}\right)$ and obtained the alkoxyamine $\mathbf{5 . 3}$ in $98 \%$ yield.

\subsection{Alkoxyamines via Addition of C-Radicals to Nitrones or Nitroso Compounds}

C-centered radicals add very rapidly to nitroso compounds or nitrones affording nitroxides which react further in the presence of an excess of C-radicals to yield alkoxyamines as final products (Scheme 


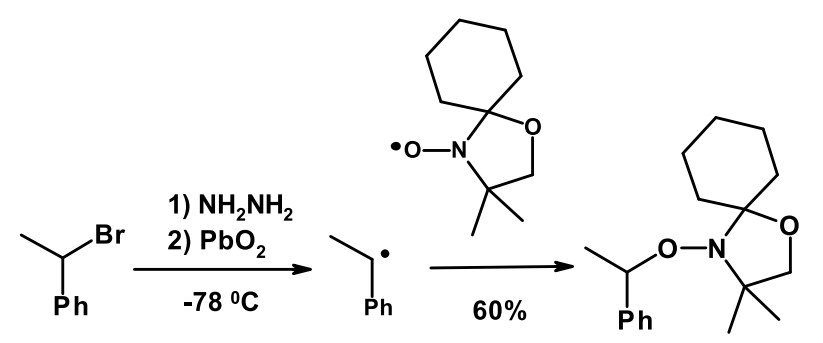

3.1

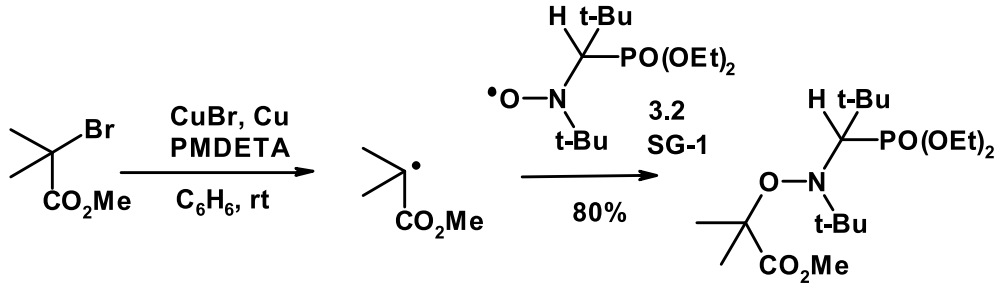

3.3

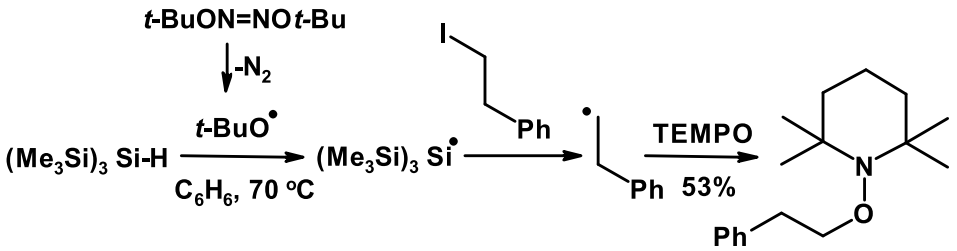

3.4
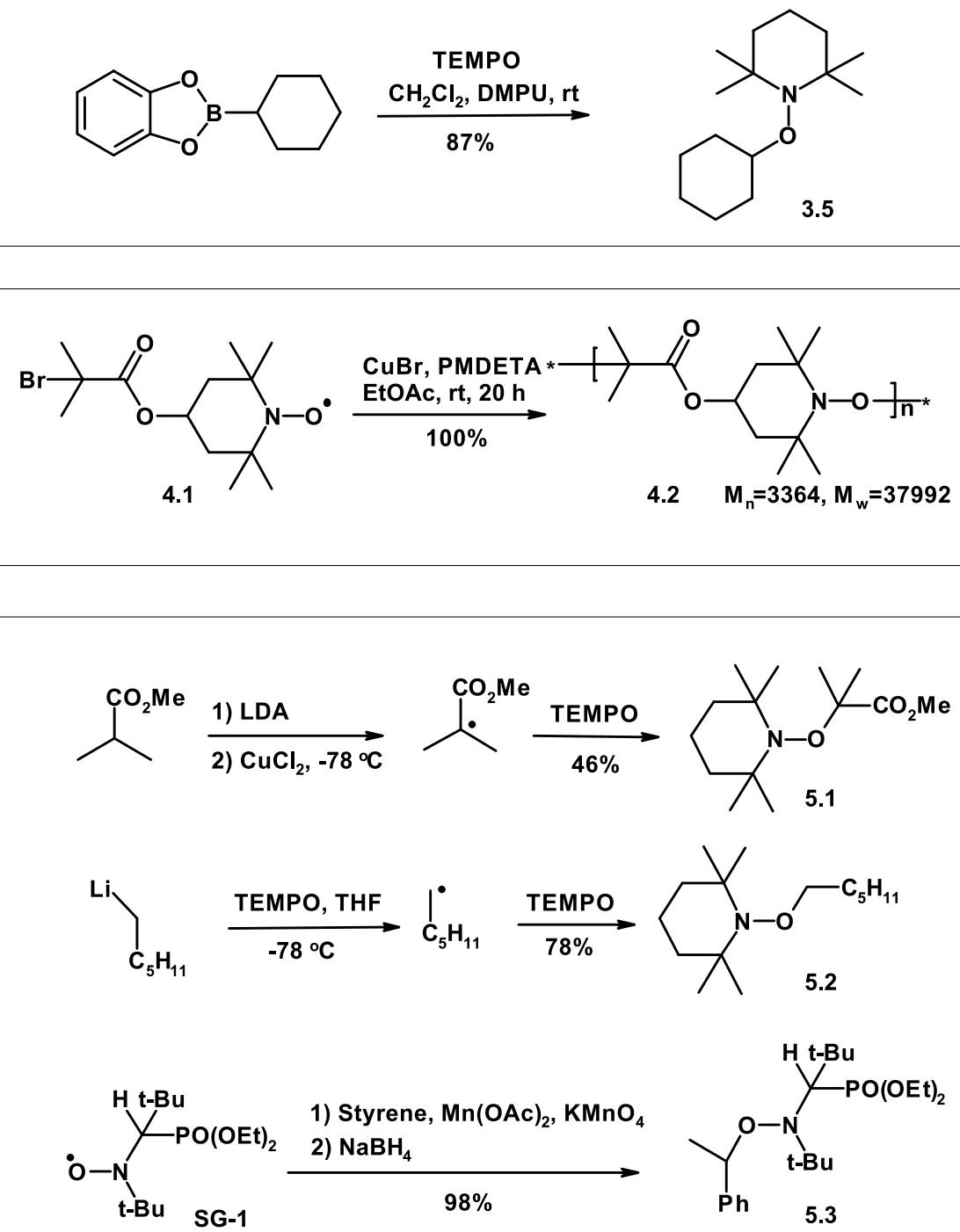


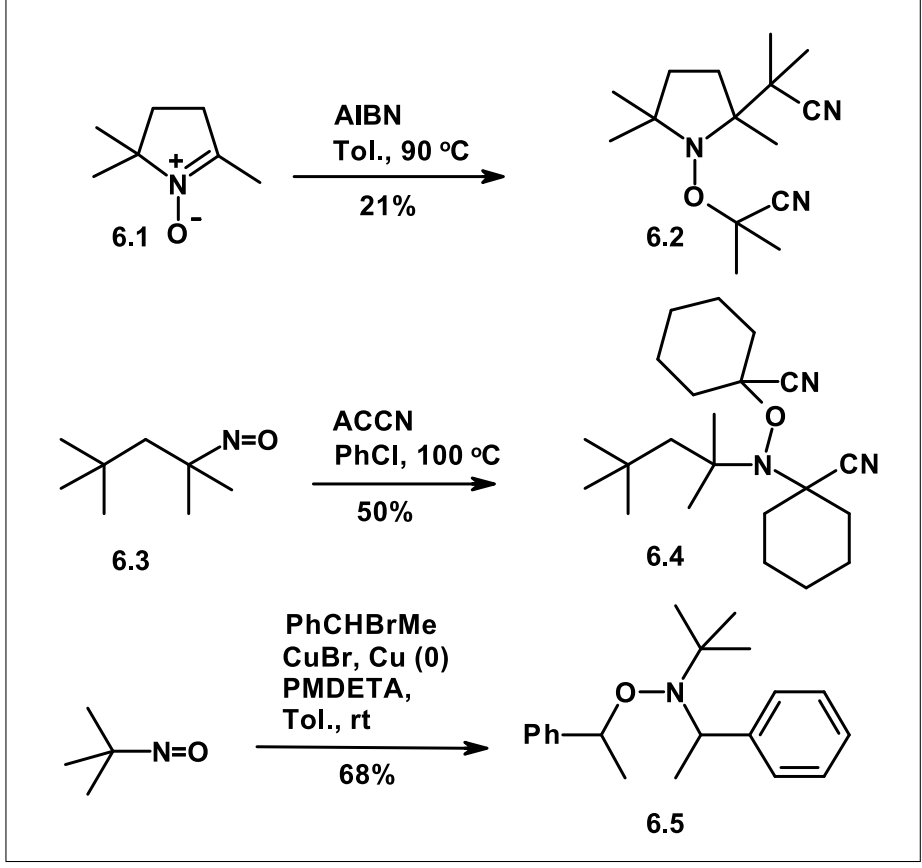

Scheme 6

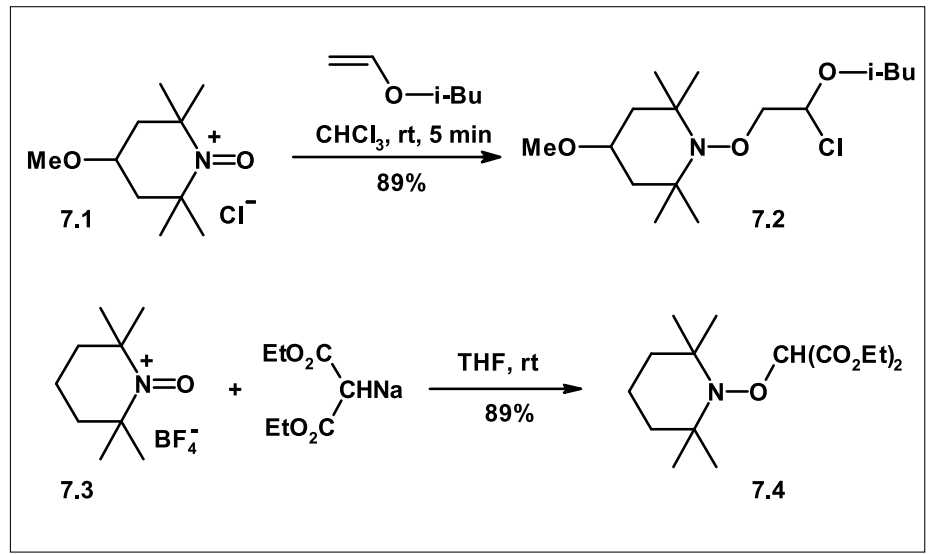

Scheme 7.

6). For example, decomposition of AIBN in the presence of nitrone $\mathbf{6 . 1}$ yields the alkoxyamine 6.2 [38]. Analogously 1,1'azo-bis(cyclohexane-carbonitrile) (ACCN) and 2,2,4-trimethyl-4-nitrosopentane $\mathbf{6 . 3}$ afford 6.4. Grubbs et al. [39] used the same principle but generated the $\mathrm{C}$-radicals from phenethyl bromide and $\mathrm{CuBr}$ and obtained the alkoxyamine 6.5 in $68 \%$ yield.

\subsection{Alkoxyamines from Oxoammo- nium Salts}

Several syntheses of alkoxyamines use the well-known [40] oxoammonium salts which are readily available from nitroxides via one-electron oxidation with halogens or via acid-promoted disproportionation. Thus, smooth electrophilic addition [41] of oxoammonium salts to vinyl ethers, enamines or electron-rich olefins affords functionalized alkoxyamines as exemplified by the addition of $\mathbf{7 . 1}$ to vinyl iso-butylether affording 7.2. (Scheme 7). Styrene reacts similarly with 1-oxo-2,2,6,6-tetramethylpiperidinium chloride or bromide but a free radical mechanism was postulated [42] in this case. The intermediacy of C-radicals is considered [43] also in the alkoxyamine syntheses [43][44] in which enolates are coupled with the oxoammonium salts. An example is the formation of the alkoxyamine 7.4 from the Na salt of diethyl malonate and tetramethylpiperidin-1-oxoammonium tetrafluoroborate $\mathbf{7 . 3}$ [43].

\subsection{Miscellaneous Syntheses of Alkoxyamines}

Under normal conditions nitroxides do not add to alkenes. However, at elevated temperatures they undergo [45][46] a slow reaction with acrylonitrile, methyl acrylate and styrene to give bis-nitroxide adducts, e.g. 8.1 (Scheme 8) [46]. With alkenes such as methyl methacrylate containing an allylic hydrogen the major reaction observed was hydrogen abstraction. Ketenes are more reactive and give mixed acyloxy alkoxyamines, for instance 8.2 [47]. Nitroxides can be readily transformed into anions of the corresponding hydroxylamines, either directly via one-electron reduction with sodium or potassium in THF or via reduction into hydroxylamines and their deprotonation. The hydroxylamine anions can be alkylated with reactive alkyl halides to give alkoxyamines, for example 8.3 [48]. O-allyl alkoxyamines, for instance 8.4 [49], are accessible via Meisenheimer rearrangement of the readily available $t$-amine oxides.

\section{Properties of Alkoxyamines}

Alkoxyamines are colorless solids or liquids that can be handled in air. They are significantly less basic than the corresponding amines and therefore not sensitive to carbon dioxide. In fact, the $\mathrm{pK}_{\mathrm{a}}$ of protonated alkoxyamines is in the range 1.5-5, depending on their structure, which are some 5-6 orders of magnitude less than the parent amines [50]. A very important property is the relatively low bond dissociation energy (BDE) of the $\mathrm{NO}-\mathrm{C}$ bond. In fact, thermally induced homolysis of alkoxyamines generates in most cases the persistent nitroxide and reactive $\mathrm{C}$-centered radical, path (a) in Scheme 9.

This NO-C BDE depends on several factors [24][51-56] such as degree of ste- 


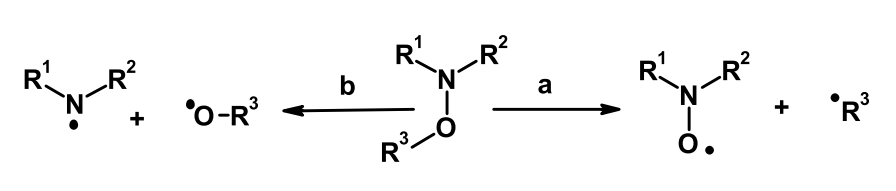

Scheme 9.

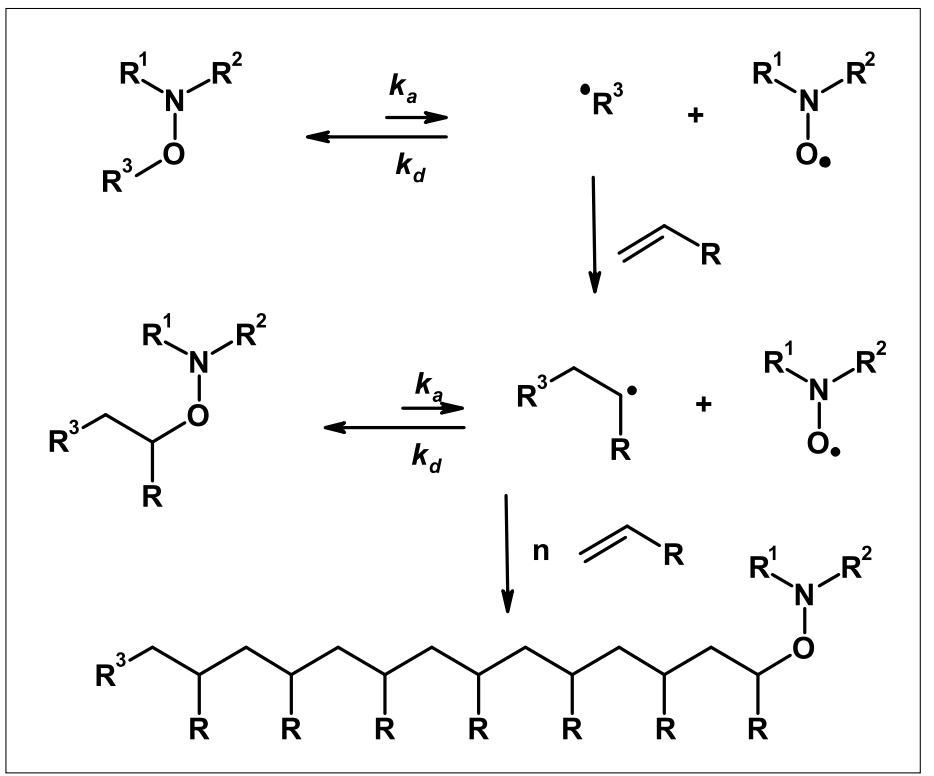

Scheme 10.

ric compression around the $\mathrm{C}-\mathrm{O}$ bond, stabilities of radicals formed, polar factors or hydrogen bonding. For example, in the series O-methylTEMPO, O-benzylTEMPO, O-(1-phenylethyl)TEMPO and O-cumylTEMPO the BDE of the NO-C bond is $47.1,34.7,30.8$ and $26.2 \mathrm{kcal} / \mathrm{mol}$, respectively [57]. The alternative cleavage into aminyl and alkoxy radical, path (b), is significant only (see Section 6) if non-stabilized primary or secondary C-radical would be formed. Alkoxyamines are quite stable at room temperature but those prone to homolysis should be stored at $0{ }^{\circ} \mathrm{C}$ or below for longer periods of time.

\section{Alkoxyamines in Macromolecular Chemistry}

\subsection{Alkoxyamines in Living Radical Polymerization}

Radical polymerization (RP) is one of the most important methods for making polymers. The process tolerates trace amounts of oxygen or monomer stabilizers and can be performed under relatively undemanding and broadly varying conditions, in solution or in bulk, at room or elevated temperature, in organic solvents or in water. A variety of monomers is available and copolymers with unique material properties can be made. In fact, around $50 \%$ of industrial polymers are made via RP to- day. However, the conventional RP does not allow polymers to be prepared with defined molecular weight or narrow molecular weight distribution, defined chain end functionalities or advanced polymeric architectures such as e.g. block-, combor star copolymers. Until recently, such polymers could be made only by means of sophisticated living polymerizations [58]. First attempts to achieve living radical polymerization (LRP) were described by Otsu in 1982 [59]. Since then several techniques [60] for LRP have been developed and synthesis of complex polymeric architectures via LRP has become state of the art these days. Amongst the most powerful LRP methods are atom transfer radical polymerization (ATRP), reversible addition-fragmentation chain transfer (RAFT) and nitroxide-mediated living radical polymerization (NMP) in which alkoxyamines play a crucial role. The history of the NMP discovery was published [61] recently and the huge NMP literature has been reviewed [60][62-64] several times. Hence, rather than discussing details, the key role of alkoxyamines in NMP will be highlighted here. In fact, the principle of NMP is the reversible, thermally induced dissociation of the weak NO-C bond of alkoxyamines to afford persistent nitroxide radicals and reactive $\mathrm{C}$-centered radicals as depicted in Scheme 10. If monomer is present, one or few monomer molecules add to the $\mathrm{C}$ - radical. The so generated new radical then reversibly couples with nitroxide to reform the alkoxyamine. The result of this many times repeated elementary step is a polymeric chain bearing the $\mathrm{R}^{3}$ group of the initial alkoxyamine at its beginning and nitroxide group at its end.

As the equilibrium is shifted far to the alkoxyamine state, the concentration of C-radicals stays low during the polymerization. Hence, bimolecular termination reactions of C-radicals such as coupling or disproportionation are much less important compared to conventional RP; however they never stop completely. Consequently, an excess of nitroxide radicals builds up and assures high selectivity of the coupling between nitroxides and C-radicals over $\mathrm{C}$-radical termination. This phenomenon is known as the persistent radical effect [65][66]. As all chains grow at the same rate, polymers with low polydispersity (PD = mass average molecular weight $\mathrm{M}_{\mathrm{w}}$ /number average molecular weight $M_{n}$ ), of 1.11.3, are obtained. Polymerization with a second monomer added to a homopolymer terminated with alkoxyamine groups will produce a block copolymer. For a successful NMP, the values of $k_{a}, k_{d}$ and the equilibrium constant $\mathrm{K}=\mathrm{k}_{\mathrm{a}} / \mathrm{k}_{\mathrm{d}}$ must be within a defined range [67]. For this reason NMP with the currently available nitroxides has to be conducted at rather elevated temperatures, typically at $100-130{ }^{\circ} \mathrm{C}$ to achieve reasonably fast reactions. Moderate success in achieving faster polymerization was obtained using diverse accelerating additives [68-70].

Two approaches have been used to perform NMP. In the first method, the starting alkoxyamine is formed in the monomer via in situ reaction of nitroxide and C-radicals generated from a conventional azoor peroxide initiator. This approach is not optimal due to the various side reactions accompanying the alkoxyamine formation. Nowadays, NMP is executed almost exclusively with pure alkoxyamines, often called 'unimer' or 'unimolecular initiator'. Superior results are obtained with this approach because the initiating $\mathrm{C}$-radicals and nitroxide radicals are generated in an exact $1: 1$ ratio by dissociation of the unimer. TEMPO-based alkoxyamines used in the early days, e.g. 2.2, 2.3 or $\mathbf{2 . 4}$ were effective only with styrene monomers. New alkoxyamines which induce efficient NMP of styrene, esters and amides of acrylic acid, 4-vinylpyridine, $\mathrm{N}$-vinylpyrrolidone or dienes have been developed since then. They are derived from open chain or highly hindered cyclic nitroxides. Representative examples are compounds 11.1 [71], 11.2 [72], $\mathbf{1 1 . 3}$ [73][74], 11.4 [73][75], 11.5 [76] or $\mathbf{1 1 . 6}$ [23] (Scheme 11).

Thus, increased steric hindrance or ring size of cyclic alkoxyamines increases their 
<smiles>[R]ON(C(c1ccccc1)C(C)C)C(C)(C)C</smiles>

11.1<smiles>[R]ON1C(C)(CC)CC(=O)C(C)C1(C)CC</smiles><smiles>[R]N(CC)C(C(=O)OCC)C(C)(C)C</smiles>

11.2<smiles>[R]ON1C(CC)(CC)CC(=O)CC1(CC)CC</smiles><smiles>CCC1(CC)C(=O)N(C(C)(C)C)CC(C)(C)N1O[Na]</smiles>$$
11
$$<smiles>[R]ON1C(C)(CC)CC(=O)NC(C)C1(C)CC</smiles>

\section{$\mathrm{R}=\mathrm{PhCHCH}_{3}$}

\subsection{Design of Thermo Reversible Polymers with Alkoxyamines}

The propensity of alkoxyamines to undergo thermal homolysis was used by Takahara and coworkers [86] to prepare graft polymers such as $\mathbf{1 2 . 3}$ via reversible radical crossover of alkoxyamine units attached to side chain of poly(methacrylic ester) $\mathbf{1 2 . 1}$ and polystyrene 12.2 (Scheme 12). The obtained graft polymer could be transformed reversibly to the starting materials by heating with excess amount of alkoxyamine 12.4. Very recently, the same authors used this principle to develop a novel dynamic polymer cross-linking system [87] consisting of polymers $\mathbf{1 2 . 1}$ and 12.5. The crosslinked polymer $\mathbf{1 2 . 6}$ obtained by heating the linear polymers $\mathbf{1 2 . 1}$ and $\mathbf{1 2 . 5}$ at $100{ }^{\circ} \mathrm{C}$ under argon can be de-crosslinked by heating with an excess of alkoxyamine 12.4. efficiency as NMP mediators. However, Siegenthaler and Studer demonstrated that control of polymerization breaks down with too bulky alkoxyamines [52].

Versatility of alkoxyamines in synthesis of complex molecular architectures on laboratory scale has been amply demonstrated; the reader is referred to the cited reviews. The latest work indicates that NMP is being increasingly used in supramolecular chemistry, e.g. for grafting of polymeric carpets on carbon nanotubes [77] or polymeric microspheres [78], preparation of functionalized micelles and nanoparticles [79] or synthesis of terpyridine terminated polymers [80] usable as building blocks for supramolecular block copolymers obtained via chelation with ruthenium. The self-organization of well-de- fined macromolecular building blocks synthesized by NMP and other LRP techniques into unprecedented nanostructures was reviewed recently [81]. Remarkable progress was achieved towards realization of NMP in aqueous emulsion [82]. NMP in ionic liquid [83] or supercritical $\mathrm{CO}_{2}$ [84][85] were also successful. Moreover, NMP is no longer a pure laboratory method. In fact, the first application of NMP for tonne scale industrial synthesis of amphiphilic acrylic block copolymers for use as pigment dispersants was reported recently [73][75].

However, despite the tremendous progress made in the last years, important challenges such as NMP of methacrylates or vinyl acetate, or fast polymerization below $100{ }^{\circ} \mathrm{C}$ remain.<smiles>CCCC(C)(CC(C)(C)CC(C)(C)C(C)(C)CC(C)(C)C(=O)OC1CC(C)(C)N(OC(C)c2ccccc2)C(C)(C)C1)C(C)(C)C</smiles><smiles>COC1CC(C)(C)N(O[C@H](CC(C)c2ccccc2)c2ccccc2)C(C)(C)C1</smiles><smiles>COC1CC(C)(C)N(OC(C)c2ccccc2)C(C)(C)C1</smiles>

12.5<smiles>CCCC(C)(C)CC(C)(C)C(=O)OCC(ON1C(C)(C)CC(OC)CC1(C)C)c1ccccc1</smiles>

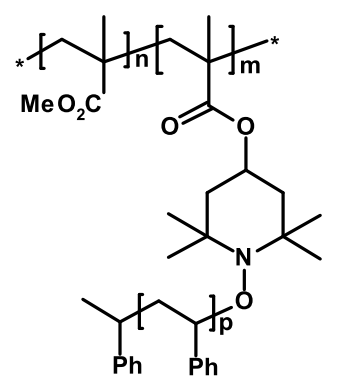

12.3

graft polymer

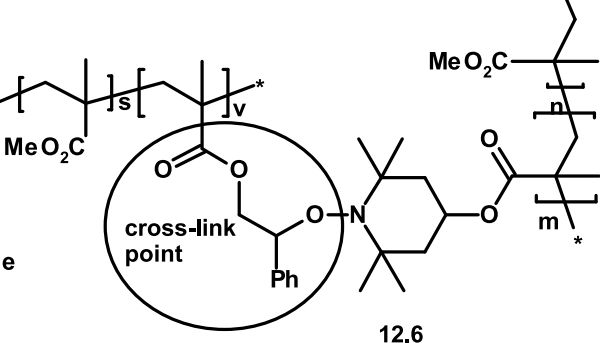

cross-linked polymer

\section{Alkoxyamines in Organic Synthesis}

The persistent radical effect (PRE) [65][66] plays an important role not only in controlling the mechanism of NMP. Studer and coworkers [65][88] and others [89] showed that it can be used for the design of new radical addition and cyclization reactions. The concept is demonstrated on Scheme 13 [90]. Heating the alkoxyamine 13.1 at $130{ }^{\circ} \mathrm{C}$ in $t$-butanol containing $10 \%$ camphorsulfonic acid induces reversible homolysis of the NO-C bond. The radical 13.2 disappears via irreversible dimerization and reversible 5-exo (major) and 6-endo (minor) cyclization affording radicals $\mathbf{1 3 . 3}$ and 13.5. The latter are captured by TEMPO in rapid, irreversible reactions affording the isomerized alkoxyamines 13.4 and 13.6. The PRE efficiently controls the whole process. In fact, the original irreversible disappearance of 13.2 leads very soon to a build-up of an excess of TEMPO which assures that paths (a)-(c) are highly preferred over (d). Moreover, the NO-C bond in $\mathbf{1 3 . 1}$ is significantly weaker [91] than those in $\mathbf{1 3 . 4}$ or 13.6 which consequently do not undergo homolysis under reaction conditions. The resulting irreversible trapping of $\mathbf{1 3 . 3}$ or 13.5 with TEMPO pulls the reaction over to products 13.4 and 13.6.

The alkoxyamine functionality can be readily replaced [92][93] with different functional groups. Hence, these cyclizations are emerging as valuable, environmentally benign alternatives to the toxic state of the art organotin reagents. Thus, alkoxyamines derived from the so-called SG-1 nitroxide were used for the synthesis of lactones and lactames as demonstrated by the cyclization of 14.1 into 14.2 (Scheme 14) [89]. Recent developments based on thermolysis of alkoxyamines are carbon monoxide trapping reaction [94] with subsequent Friedel- 


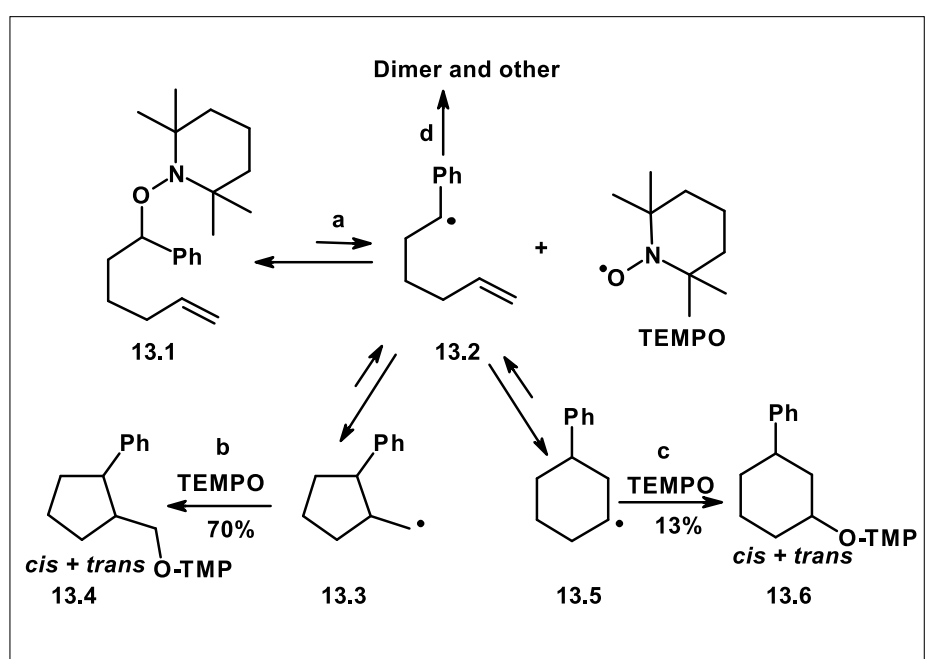

Scheme 13.

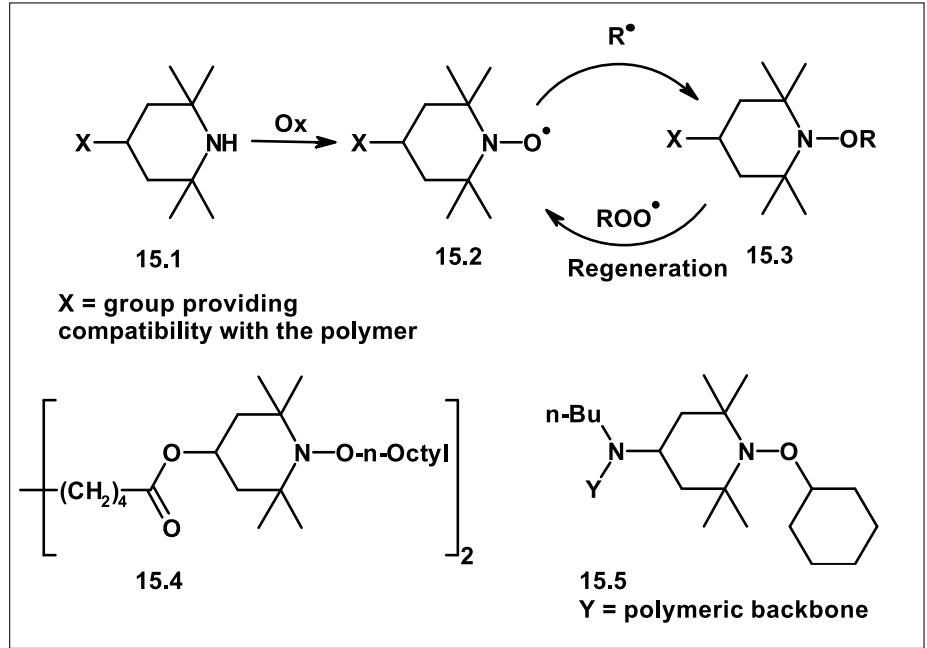

Scheme 15

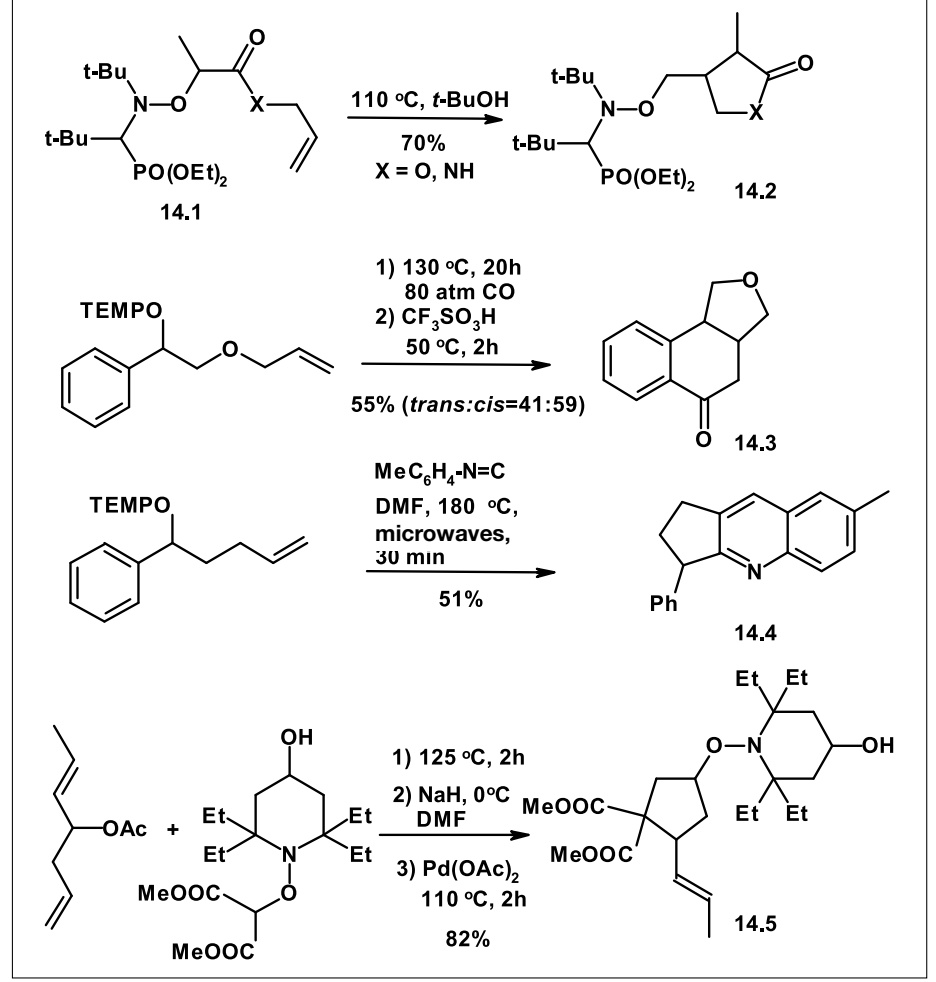

Scheme 14

Crafts cyclization to afford 3,4-cyclopenta1-tetralones, e.g. 14.3, trapping of isonitriles to yield quinolines [95], e.g. $\mathbf{1 4 . 4}$ or radical carboaminoxylation [96] with subsequent Trost-Tsuji allylation as the example $\mathbf{1 4 . 5}$ demonstrates.

\section{Applications of Alkoxyamines in Stabilization of Polymers}

Almost every synthetic polymer undergoes degradation reactions in the presence of oxygen or under exposure to heat or light. A variety of antioxidants, heat and light stabilizers has been developed [97] to prevent or at least significantly retard these detrimental processes. Derivatives of 2,2,6,6-tetramethyl-piperidine $\mathbf{1 5 . 1}$ (Scheme 15) represent a very important family of light and heat stabilizers (often abbreviated as HAS) of which thousands of tonnes are used by the polymer industry every year. The key step of the stabilization mechanism is in situ oxidation of $\mathbf{1 5 . 1}$ into nitroxide radicals $\mathbf{1 5 . 2}$ which scavenge polymeric $\mathrm{C}$-centered radicals involved in the degradation process affording thus the alkoxyamines 15.3. The latter decompose polymeric peroxyradicals which are also responsible for polymer degradation under concomitant regeneration of 15.2. This cyclic mechanism explains the high efficiency of HAS [98-100].
HAS of type $\mathbf{1 5 . 1}$ are quite basic [97], in fact, the $\mathrm{pK}_{\mathrm{a}}$ of their conjugated acids is around 9. In special situations, e.g. if the polymer is exposed to acidic environment, protonation of $\mathbf{1 5 . 1}$ occurs. As a consequence, oxidation of $\mathbf{1 5 . 1}$ into $\mathbf{1 5 . 2}$ and therefore the stabilization action of HAS is inhibited. Pure alkoxymine stabilizers, for instance 15.4 [101] with $\mathrm{pK}_{\mathrm{a}} \sim 4.5$ are used in such cases instead of the free HAS amine 15.1. Nitroxides $\mathbf{1 5 . 2}$ are non basic species, e.g. the $\mathrm{pK}_{\mathrm{a}}$ of protonated TEM$\mathrm{PO}$ was reported [102] to be -5.5 . It should be mentioned that only alkoxyamines that are not prone to easy homolysis, i.e. those with relatively strong $\mathrm{NO}-\mathrm{C}$ bonds are suitable for this application. The reason is that they must withstand elevated temperatures $\left(>200{ }^{\circ} \mathrm{C}\right)$ when they are incorporated into the polymer in an extruder.

Recently, special alkoxyamines such as 15.5 have been introduced as environmentally friendly flame retardant additives for polymers [103]. Their mode of action is still matter of debate, one hypothesis is that during very high temperatures encountered in the burning polymer the predominant homolysis of the N-OC bond takes place ( $c f$. path (b), Scheme 9). The two reactive radicals generated, cyclohexyloxyl and aminyl, are proposed to promote, depending on the polymer structure, chain scission or cross linking of the burning polymer, hence its physical consistency, which in turn should influence its burning properties.

\section{Alkoxymines in Fluorescence Sensing and Imaging}

Nitroxides are very effective quenchers of excited electronic states [104][105]. Consequently, fluorescent molecules attached to nitroxides show strongly reduced fluorescence due to intramolecular quenching of fluorophore's excited state. The fluo- 
rescence is restored by transformation of nitroxides into diamagnetic alkoxyamines via C-radical trapping or into hydroxylamines by reduction. Several highly sensitive sensing or imaging methods were developed using this principle [106-115]. The concept is demonstrated with the following three examples. Bottle and coworkers [111] used the profluorescent nitroxide 16.1 to study the early thermooxidative degradation phase of polypropylene (PP). He measured the fluorescence of the alkoxyamine 16.2 formed by trapping polymer alkyl radicals generated during the degradation of PP with 16.1 (Scheme 16). The radicals were observed before any change in the polymer was detectable using either chemiluminiscence or infrared spectroscopy. Scaiano and coworkers [112] applied the profluorescent nitroxide $\mathbf{1 6 . 3}$ for fluorescent imaging of radicals generated from photoinitiators in poly(methyl methacrylate) (PMMA). Irradiation of thin PMMA film containing 16.3 and photoinitiator through a mask with $10 \mu \mathrm{m}$ features produced finely resolved fluorescent images in which the highly fluorescent regions are those in which radicals have been photochemically generated and trapped to generate highly fluorescent alkoxyamine 16.4. Parent and coworkers [114] employed the profluorescent nitroxide $\mathbf{1 6 . 5}$ to measure the concentration of TEMPO terminated chains in polystyrene prepared by NMP. The nonfluorescent TEMPO end groups were exchanged by thermal equilibration with $\mathbf{1 6 . 5}$ and the so generated fluorescent polymeric chains were quantified via spectrofluorimetry.

\section{Conclusions}

The chemistry of alkoxyamines has attracted much interest over the past decade. Alkoxyamines are key species in the booming living radical polymerization by which increasingly complex macromolecular structures and supramolecular objects are made. Moreover, this method has been successfully moved from laboratory into large-scale industrial production. New alkoxyamines are finding use as flame retarding additives in synthetic polymers. Environmentally friendly, sophisticated organic radical reactions or highly sensitive applications in sensing or fluorescence imaging are emerging. To meet the demand for specific applications, versatile synthetic methods for alkoxyamines have been and continue to be developed.

Received: October 16, 2006

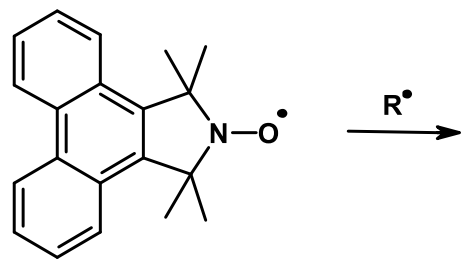

16.1 profluorescent<smiles>[R]ON1C(C)(C)c2c(c3ccccc3c3ccccc23)C1(C)C</smiles>

16.2 fluorescent

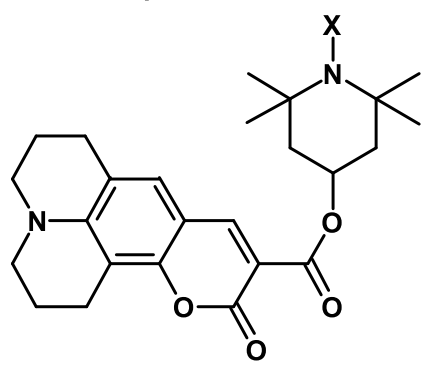

16.3X $=0^{\circ}$ profluorescent 16.4 X= O-alkyl, fluorescent<smiles>CC1(C)CC(OC(=O)c2cccc3ccccc23)CC(C)(C)N1[O]</smiles>

16.5 profluorescent

Scheme 16.

[1] E.G. Rozantsev, 'Free Nitroxyl Radicals', Plenum Press, New York, 1970.

[2] L.B. Volodarsky, V.A. Reznikov, V.I. Ovcharenko, 'Synthetic Chemistry of Stable Nitroxides', CRC Press, Boca Raton, 1994.

[3] A. Nilsen, R. Braslau, J. Polym. Sci., Part A: Polym. Chem. 2005, 44, 697.

[4] N. Naik, R. Braslau, Tetrahedron 1998, $54,667$.

[5] K. Hideg, T. Kalai, C.P. Sar, J. Heterocycl. Chem. 2005, 42, 437.

[6] M.T. Lemaire, Pure Appl. Chem. 2004, 76, 277.

[7] J.F.W. Keana, Chem. Rev. 1978, 78, 37.

[8] M.E. Brik, Heterocycles 1995, 41, 2827.

[9] K. Doser, in 'Houben-Weyl', Vol. E 16a, 1990, p. 395.

[10] R. Andree, J.F. Kluth, in 'Houben-Weyl', Vol. E 16a, 1990, pp. 296.

[11] A.L.J. Beckwith, V.W. Bowry, K.U. Ingold, J. Am. Chem. Soc. 1992, 114, 4983.

[12] V.W. Bowry, K.U. Ingold, J. Am. Chem. Soc. 1992, 114, 4992.

[13] D. Wang, Z. Wu, Macromolecules 1998, $31,6727$.

[14] C.J. Hawker, G.G. Barclay, A. Orellana, J. Dao, W. Devonport, Macromolecules 1996, 29, 5245.

[15] Y. Miura, K. Hirota, H. Moto, B. Yamada, Macromolecules 1998, 31, 4659.

[16] R. Braslau, L.C. Burrill, II, M. Siano, N. Naik, R.K. Howden, L.K. Mahal, Macromolecules 1997, 30, 6445.

[17] H.-J. Kirner, F. Schwarzenbach, P.A. Van Der Schaaf, A. Hafner, V. Rast, M. Frey, P. Nesvadba, G. Rist, Adv. Synth. Catal. 2004, 346, 554.

[18] C.-X. Zhao, H.-Y. He, Y.-L. Qu, J. Fluorine Chem. 1995, 72, 215.
[19] L.J. Johnston, M. Tencer, J.C. Scaiano, J. Org. Chem. 1986, 51, 2806.

[20] J.E. Babiarz, G.T. Cunkle, A.D. DeBellis, D. Eveland, S.D. Pastor, S.P. Shum, $J$ Org. Chem. 2002, 67, 6831.

[21] K. Matyjaszewski, B.E. Woodworth, X. Zhang, S.G. Gaynor, Z. Metzner, Macromolecules 1998, 31, 5955.

[22] D. Benoit, V. Chaplinski, R. Braslau, C.J. Hawker, J. Am. Chem. Soc. 1999, 121, 3904.

[23] P. Nesvadba, L. Bugnon, R. Sift, J. Polym. Sci., Part A: Polym. Chem. 2004, 42, 3332.

[24] E. Beaudoin, D. Bertin, D. Gigmes, S.R.A. Marque, D. Siri, P. Tordo, Eur. J. Org. Chem. 2006, 1755.

[25] R. Braslau, A. Tsimelzon, J. Gewandter, Org. Lett. 2004, 6, 2233.

[26] K.A. Moffat, P.M. Kazmaier, G.K. Hamer, M.K. Georges, US Patent No. 5498679, 1996.

[27] C. Ollivier, R. Chuard, P. Renaud, Synlett 1999, 807.

[28] P. Nesvadba, L. Bugnon, WO Patent No. 2004026915, 2004.

[29] W. Thiessen, T. Wolff, Des. Monomers Polym. 2005, 8, 397.

[30] U. Jahn, J. Org. Chem. 1998, 63, 7130.

[31] K.-H. Ahn, Y. Kim, Synth. Commun. 1999, 29, 4361.

[32] T. Nagashima, D.P. Curran, Synlett 1996, 330.

[33] A.J. Herrera, A. Studer, Synthesis 2005, 1389.

[34] J. Dao, D. Benoit, C. Hawker, J. Polym. Sci., Part A: Polym. Chem. 1998, 36, 2161.

[35] M. Bothe, G. Schmidt-Naake, Macromol. Rapid Commun. 2003, 24, 609.

[36] S. Flakus, K. Mandel, M. Bartsch, G. 
Schmidt-Naake, Macromol. Rapid Commun. 2005, 26, 1698.

[37] T. Krause, W.D. Habicher, M. Messerschmidt, B.I. Voit, Des. Monomers Polym. 2004, 7, 391.

[38] M.-O. Zink, A. Kramer, P. Nesvadba, Macromolecules 2000, 33, 8106.

[39] R.B. Grubbs, J.K. Wegrzyn, Q. Xia, Chem. Commun. 2005, 80

[40] N. Merbouh, J.M. Bobbitt, C. Brückner, Org. Prep. Proced. Int. 2004, 36, 1.

[41] T. Takata, Y. Tsujino, S. Nakanishi, K. Nakamura, E. Yoshida, T. Endo, Chem. Lett. 1999, 937.

[42] S. Kobatake, H.J. Harwood, R.P. Quirk, D.B. Priddy, J. Polym. Sci., Part A: Polym. Chem. 1998, 36, 2555.

[43] M. Schaemann, H.J. Schaefer, Synlett 2004, 1601.

[44] T. Ren, Y.-C. Liu, Q.-X. Guo, Bull. Chem. Soc. Jpn. 1996, 69, 2935

[45] T.J. Connolly, J.C. Scaiano, Tetrahedron Lett. 1997, 38, 1133.

[46] F. Aldabbagh, W.K. Busfield, I.D. Jenkins, S.H. Thang, Tetrahedron Lett. 2000, 41 , 3673.

[47] A.D. Allen, B. Cheng, M.H. Fenwick, B. Givehchi, H. Henry-Riyad, V.A. Nikolaev, E.A. Shikhova, D. Tahmassebi, T.T. Tidwell, S. Wang, J. Org. Chem. 2001, 66 , 2611.

[48] B. Moon, M. Kang, Macromol. Res. 2005 13, 229.

[49] D.E. Bergbreiter, B. Walchuk, Macromolecules 1998, 31, 6380 .

[50] P. Nesvadba, Unpublished results.

[51] D. Bertin, D. Gigmes, C. Le Mercier S.R.A. Marque, P. Tordo, J. Org. Chem. 2004, 69, 4925.

[52] K.O. Siegenthaler, A. Studer, Macromolecules 2006, 39, 1347

[53] G. Ananchenko, E. Beaudoin, D. Bertin, D. Gigmes, P. Lagarde, S.R.A. Marque, E. Revalor, P. Tordo, J. Phys. Org. Chem. 2006, 19, 269.

[54] Y. Guillaneuf, O. Guerret, D. Gigmes, S.R.A. Marque, P. Tordo, D. Bertin, Polym. Prepr., Am. Chem. Soc., Div. Polym. Chem., 2005, 46, 188.

[55] S. Marque, H. Fischer, E. Baier, A. Studer, J. Org. Chem. 2001, 66, 1146.

[56] O. Guerret, J.-L. Couturier, F. Chauvin, H El-Bouazzy, D. Bertin, D. Gigmes, S. Marque, H. Fischer, P. Tordo, ACS Symposium Series, 'Advances in controlled/living radical polymerization', 2003, 854, 412 .

[57] P. Marsal, M. Roche, P. Tordo, P. de Claire, J. Phys. Chem. A 1999, 103, 2899.

[58] O.W. Webster, Science 1991, 887.

[59] T. Otsu, J. Polym. Sci., Part A: Polym. Chem. 2000, 38, 2121.

[60] G. Moad, D.H. Solomon, in 'Living Radical Polymerization', Elsevier, Amsterdam, 2006, p. 451.

[61] D.H. Solomon, J. Polym. Sci., Part A: Polym. Chem. 2005, 43, 5750.

[62] C.J. Hawker, A.W. Bosman, E. Harth, Chem. Rev. 2001, 101, 3661.
[63] D.A. Shipp, J. Macromol. Sci., Polym. Rev. 2005, C45, 171.

[64] A. Studer, T. Schulte, Chem. Rec. 2005, 5, 27.

[65] H. Fischer, Chem. Rev. 2001, 101, 3581 .

[66] A. Studer, Chem. Eur. J. 2001, 7, 1159.

[67] H. Fischer, M. Souaille, Macromol. Symp. 2001, 174, 231.

[68] C.-C. Chang, A. Studer, Macromolecules 2006, 39, 4062.

[69] A. Debuigne, T. Radhakrishnan, M.K. Georges, Macromolecules 2006, 39 , 5359.

[70] H. Jianying, L. Jian, L. Minghua, L. Qiang, D. Lizong, Z.Yousi, J. Polym. Sci., Part A: Polym. Chem. 2005, 43, 5246.

[71] D. Benoit, E. Harth, P. Fox, R.M. Waymouth, C.J. Hawker, Macromolecules 2000, 33, 363.

[72] C. Le Mercier, S. Acerbis, D. Bertin, F. Chauvin, D. Gigmes, O. Guerret, M. Lansalot, S. Marque, F. Le Moigne, H. Fischer, P. Tordo, Macromol. Symp. 2002 182, 225.

[73] C. Auschra, E. Eckstein, R. Knischka, F. Pirrung, P. Harbers, Eur. Coat. J. 2004, 6 , 26.

[74] H. Fischer, A. Kramer, S.R.A. Marque, P. Nesvadba, Macromolecules 2005, 38 , 9974.

[75] C. Auschra, E. Eckstein, R. Knischka, P. Nesvadba, Asia Pacific. Coat. J 2003, 20.

[76] C. Wetter, J. Gierlich, C.A. Knoop, C. Mueller, T. Schulte, A. Studer, Chem. Eur. J. 2004, 10, 1156

[77] X.-D. Zhao, X.-H. Fan, X.-F. Chen, C.-P. Chai, Q.-F. Zhou, J. Polym. Sci., Part A Polym. Chem. 2006, 44, 4656.

[78] K. Bian, M.F. Cunningham, Polymer 2006, 47, 5744

[79] R.K. O'Reilly, M.J. Joralemon, C.J. Hawker, K.L. Wooley, J. Polym. Sci., Part A: Polym. Chem. 2006, 44, 5203.

[80] C. Ott, B.G.G. Lohmeijer, D. Wouters, U.S. Schubert, Macromol. Chem. Phys. 2006, 207, 1439.

[81] J.-F. Lutz, Polym. Int. 2006, 55, 979.

[82] J. Nicolas, B. Charleux, S. Magnet, J. Polym. Sci., Part A: Polym. Chem. 2006, 44 , 4142.

[83] H. Zhang, K. Hong, J.W. Mays, Polym. Bull., Heidelberg, Ger., 2004, 52, 9.

[84] R. McHale, F. Aldabbagh, P.B. Zetterlund, H. Minami, M. Okubo, Macromolecules 2006, 39, 6853.

[85] J. Ryan, F. Aldabbagh, P.B. Zetterlund, M Okubo, Polymer 2005, 46, 9769

[86] Y. Higaki, H. Otsuka, A. Takahara, Macromolecules 2004, 37, 1696.

[87] Y. Higaki, H. Otsuka, A. Takahara, Macromolecules 2006, 39, 2121.

[88] A. Studer, Chem. Soc. Rev. 2004, 33, 267.

[89] D. Bertin, D. Gigmes, S.R.A. Marque, P. Tordo, Tetrahedron 2005, 61, 8752.

[90] A. Studer, Angew. Chem., Int. Ed. 2000, 39,1108
[91] D. Bertin, D. Gigmes, S.R.A. Marque, P. Tordo, Macromolecules 2005, 38, 2638.

[92] C.H. Honeyman, K.A. Moffat, G.K Hamer, M.K. Georges, Polymeric Materials Science and Engineering 1999, 80, 88.

[93] H. Malz, H. Komber, D. Voigt, J. Pionteck, Macromol. Chem. Phys. 1998, 199, 583.

[94] Y. Uenoyama, M. Tsukida, T. Doi, I. Ryu, A. Studer, Org. Lett. 2005, 7, 2985.

[95] B. Janza, A. Studer, Org. Lett. 2006, 8 , 1875.

[96] B. Schulte, A. Studer, Synthesis 2006 2129.

[97] H. Zweifel, 'Stabilization of Polymeric Materials', Springer, 1998

[98] F. Gugumus, Polym. Degrad. Stab. 1993, 40, 167.

[99] I. Rossi, A. Venturini, A. Zedda, J. Am. Chem. Soc. 1999, 121, 7914.

[100] F. Gugumus, Polym. Degrad. Stab. 1994 44, 299.

[101] R.L. Gray, Plastics Engineering, Brookfield, CT, United States, 1991, 47, 21.

[102] A. Janowski, I. Turowska-Tyrk, P.K. Wrona, J. Chem. Soc. Perkin Trans. 2 1985, 821

[103] J.R. Pauquet, P. Schrijver-Rzymelka, Chemical Fibers Int. 2000, 50, 468.

[104] S.A. Green, D.J. Simpson, G. Zhou, P.S Ho, N.V. Blough, J. Am. Chem. Soc. 1990 , 112, 7337.

[105] S.E. Herbelin, N.V. Blough, J. Phys Chem. B 1998, 102, 8170 .

[106] Y. Tang, F. He, M. Yu, S. Wang, Y. Li, D. Zhu, Chem. Mater. 2006, 18, 3605.

[107] S.A. Rivera, B.S. Hudson, J. Am. Chem. Soc. 2006, 128, 18

[108] V. Maurel, M. Laferriere, P. Billone, R. Godin, J.C. Scaiano, J. Phys. Chem. B 2006, 110, 16353.

[109] Y.-M. Dang, X.-Q. Guo, Appl. Spectrosc. 2006, 60, 203.

[110] B. Bognar, E. Osz, K. Hideg, T. Kalai, J. Heterocycl. Chem. 2006, 43, 81 .

[111] A.S. Micallef, J.P. Blinco, G.A. George, D.A. Reid, E. Rizzardo, S.H. Thang, S.E. Bottle, Polym. Degrad. Stab. 2005, 89 , 427.

[112] C. Coenjarts, O. Garcia, L. Llauger, J. Palfreyman, A.L. Vinette, J.C. Scaiano, J. Am. Chem. Soc. 2003, 125, 620 .

[113] C. Aliaga, A. Aspee, J.C. Scaiano, Org. Lett. 2003, 5, 4145 .

[114] M.E. Scott, J.S. Parent, S.L. Hennigar, R.A. Whitney, M.F. Cunningham, Macromolecules 2002, 35, 7628.

[115] O.G. Ballesteros, L. Maretti, R. Sastre, J.C. Scaiano, Macromolecules 2001, 34 , 6184. 